\title{
Intra-Familial Incidence and Characteristics of Hot Water Epilepsy
}

\author{
Yuksel Kaplan, Semiha G. Kurt, Hatice Karaer, Basar Sarikaya, Nerses Bebek
}

\begin{abstract}
Objective: To assess the clinical features of several members of the same family diagnosed with both hot water epilepsy (HWE) and cerebral lesions. Methods: Age at onset and types of seizure, precipitating factors, EEG findings, and neuroimages were evaluated. Results: The family consisted of six generations, including one consanguineous parent. Of eight family members diagnosed with epilepsy, seven suffered from HWE. Age at onset of seizures ranged within childhood. Seven patients with HWE experienced complex partial seizures, with or without secondary generalization; one experienced simple partial seizures as well as complex partial seizures. Three patients experienced spontaneous seizures as well as HWE. Interictal EEG revealed abnormalities in two patients. Magnetic resonance imaging revealed cerebral lesions in one patient, probably attributable to ischemic changes. Magnetic resonance images were consistent with findings of ischemic gliosis in two patients, and either demyelinating or ischemic gliosis in one patient. Conclusions: Descriptions of HWE families with different ethnic backgrounds may permit more definite conclusions regarding the mechanisms epileptogenesis, and the genetic defects that underlie this disease.
\end{abstract}

RÉSUMÉ: Incidence et caractéristiques intrafamiliales de l'épilepsie provoquée par l'eau chaude. Objectif : Le but de l'étude était de préciser les manifestations cliniques et les lésions cérébrales chez plusieurs membres de la même famille atteints d'épilepsie provoquée par l'eau chaude (EEC). Méthodes : L'âge de début et les types de crises, les facteurs précipitants, les constatations à l'EEG et la neuroimagerie ont été étudiés. Résultats : La famille est composée de six générations, incluant une union consanguine. Sept des 8 membres de la famille chez qui un diagnostic d'épilepsie avait été posé étaient atteints d'EEC. Les crises débutaient dans l'enfance. Sept patients atteints d'EEC présentaient des crises partielles complexes avec ou sans généralisation secondaire ; un patient présentait des crises partielles simples et des crises partielles complexes. Trois patients présentaient des crises spontanées et de l'EEC. L'EEG interictal a montré des anomalies chez 2 patients. L'IRM a montré des lésions cérébrales probablement attribuables à des changements ischémiques chez un patient. L'IRM était compatible avec une gliose ischémique chez 2 patients et avec une gliose démyélinisante ou ischémique chez un patient. Conclusions : La description de familles atteintes d'EEC de différentes origines ethniques pourrait mener à des conclusions plus précises sur le mécanisme de l'épileptogenèse dans cette maladie et les défauts génétiques sous-jacents.

Can. J. Neurol. Sci. 2009; 36: 575-581

The condition in which seizures are precipitated by bathing in hot water is referred to as "hot water" or "bathing" epilepsy. Isolated cases of hot water epilepsy (HWE) have been reported in diverse regions, including New Zealand, Australia, Japan, Canada, the United Kingdom, the United States of America, France, China, and Brazil ${ }^{1-4}$. A small number have also been identified in Turkey ${ }^{5-9}$.

The largest case studies of HWE patients have been performed in India by Mani et al, Gururaj et al, and Satishchandra et al, respectively ${ }^{1}$. Satishchandra et al reported that HWE accounts for 3.6-3.9\% of all epilepsy cases. They speculated that genetic factors and the high temperature of bath water may underlie this finding. Although studies report that $7-32.4 \%$ of HWE cases are found in families in which more than one individuals are affected ${ }^{1,10}$, the pathogenic and genetic mechanisms underlying the expression of HWE in humans remain to be demonstrated.
Neuroimaging data on patients with HWE have revealed largely normal findings. However, several studies have published neuroimaging data showing that HWE patients display structural cerebral lesions, such as hippocampal sclerosis, hippocampal/parahippocampal atrophy, pineal cysts, cavum septum pellucidi, cortical dysplasia, and arachnoid cysts $^{2,8,11,12}$.

From the Department of Neurology (YK), Turgut Ozal Medical Center, Malatya; Department of Neurology (SGK, HK), Department of Radiology (BS), Gaziosmanpasa University Faculty of Medicine, Tokat; Department of Neurology (NB), Istanbul University Faculty of Medicine, Istanbul, Turkey.

Received SePtember 15, 2008. Final Revisions Submitted May 11, 2009. Correspondence to: Yuksel Kaplan, Inonu Universitesi, Turgut Ozal Tip Merkezi, Noroloji Anabilim Dali, Malatya, Turkey. 
In this study, we examined a family containing several members diagnosed with both HWE and cerebral lesisons.

\section{Patients And Methods}

Our index case was a 32-year-old man admitted to our outpatient clinic following a 24-year history of seizures while bathing. Family members with similar symptoms were identified in Tokat, a city in the Middle Black Sea region of Turkey, and a pedigree was prepared in the field. Data were collected after all subjects received a detailed explanation of the study and provided informed consent. This study was performed in accordance with the Helsinki Declaration.

We obtained a detailed history of seizures from each patient. Data on personal and family medical histories, age, age at onset of seizures, types of seizures, precipitating factors, and bathing habits were gathered. Ictal symptomatology was assessed from two perspectives: that of the patients via self-description, and that of their first degree relatives who had observed the seizures. Clinical histories served as essential criteria for diagnosis. Seizures were classified according to the standards of the Commission of the International League Against Epilepsy ${ }^{13}$.

We performed detailed neurological examinations and routine laboratory tests, including hemograms, erythrocyte sedimentation rates, glucose levels, renal and liver function tests, thyroid function tests, creatine kinase levels, lipid profiles, protein electrophoresis, vitamin $\mathrm{B}_{12}$ levels, and urine analyses.

Electroencephalography (EEG) was performed using the international 10-20 montage system on a 32-channel Nihon Kohden EEG device. All records included 3-min hyperventilation and intermittent photic stimulation in the selected stimulation range of $0.5-30 \mathrm{~Hz}$.

Cranial magnetic resonance imaging (MRI) investigations were performed using a 1.5-T MRI unit (GE Signa Excite; GE Healthcare, Milwaukee, WI, USA) using an 8-channel dedicated neurovascular coil. All patients underwent routine sequences that included sagittal SE T1W, transverse propeller T2W, transverse T2W FLAIR, and coronal thin section FSE T2W. Three patients also had sagittal FSE T2 FLAIR imaging and were administered a contrast medium; contrast T1W images were obtained with transverse sequences serving as magnetization transfer sequences. In addition, each examination included diffusion imaging.

\section{RESULTS}

The complete pedigree structure consisted of six generations, 75 individuals, one consanguineous parent, and eight patients diagnosed with epilepsy. Of these, seven suffered from HWE. Three males were diagnosed with HWE alone; one deceased male patient had features similar to those of the surviving patients with HWE alone; another deceased male patient showed both HWE and other types of epilepsy; two female patients were diagnosed with both HWE and other types of epilepsy; and the mother of the index case was diagnosed with complex partial seizures (CPS) and generalized tonic-clonic seizures (GTCS) in the absence of HWE.

Figure 1 shows the pedigree structure for this family. Clinical, electrophysiological, and neuroradiologic data were collected from the surviving three male and three female family members suffering from HWE (Table).

\section{Clinical presentation of the family \\ Patient 1 (index case)}

Our index case is a 32-year-old man with consanguineous parents, who was admitted to our outpatient clinic reporting a history of seizures that occurred while bathing. These seizures began when the patient was six years old.

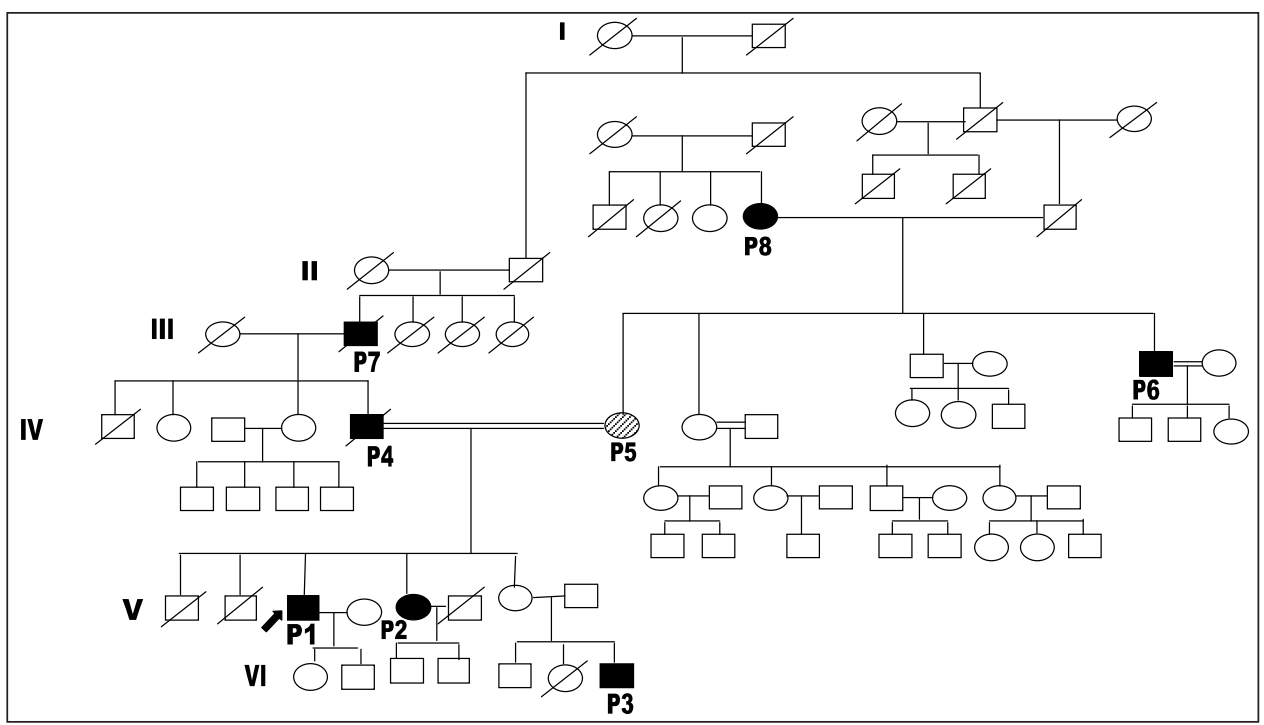

Figure 1: Pedigree of a family with hot water epilepsy. Circles and squares represent females and males, respectively. Black boxes indicate affected patients. The index case is indicated by an arrow and the number 1. 
Table: Clinical and laboratory characteristics of the patients

\begin{tabular}{|c|c|c|c|c|c|c|c|}
\hline Patient & Gender & $\begin{array}{l}\text { Age at } \\
\text { seizure onset }\end{array}$ & $\begin{array}{l}\text { Seizure } \\
\text { type }^{\mathbf{a}}\end{array}$ & Precipitating factors ${ }^{b}$ & $\mathbf{N E}^{\mathrm{c}}$ & Interictal EEG & MRI \\
\hline 1 & M & 6 & $\begin{array}{l}\text { SP } \\
\text { CP } \\
\text { SGC }\end{array}$ & $\begin{array}{l}\text { PWOH } \\
\text { TW }\end{array}$ & $\mathrm{N}$ & $\mathrm{N}$ & White matter lesions due to either demyelination or ischemia \\
\hline 2 & $\mathrm{~F}$ & 7 & $\mathrm{CP}$ & $\begin{array}{l}\text { PWOH } \\
\text { TW }\end{array}$ & $\mathrm{N}$ & $\mathrm{N}$ & $\begin{array}{l}\text { Posterior parietal subcortical lesions, probably consistent with } \\
\text { ischemic gliosis }\end{array}$ \\
\hline 3 & M & 7 & $\mathrm{CP}$ & TB & $\mathrm{N}$ & Sharp wave & - \\
\hline 4 4* & $\mathrm{M}$ & childhood & \begin{tabular}{|l|l|l}
$\mathrm{CP}$ \\
$\mathrm{GC}$
\end{tabular} & PWOH & - & - & - \\
\hline $5 * *$ & $\mathrm{~F}$ & 14 & $\begin{array}{l}\mathrm{CP} \\
\mathrm{GC} \\
\end{array}$ & - & $\mathrm{N}$ & $\mathrm{N}$ & Multiple white matter lesions due to ischemia \\
\hline 6 & M & 7 & SGC & $\begin{array}{l}\text { PWOH } \\
\text { TW }\end{array}$ & $\mathrm{N}$ & $\mathrm{N}$ & White matter lesions, probably consistent with ischemic gliosis \\
\hline $7 *$ & M & - & $\mathrm{CP}$ & $\begin{array}{l}\text { PWOH } \\
\text { TW }\end{array}$ & - & - & - \\
\hline 8 & $\mathrm{~F}$ & childhood & $\begin{array}{l}\mathrm{CP} \\
\mathrm{GC}\end{array}$ & $\begin{array}{l}\text { PWOH } \\
\text { TW }\end{array}$ & $\mathrm{N}$ & slow-wave activity & $\begin{array}{l}\text { White matter lesions due to ischemia } \\
\text { Cerebral atrophy }\end{array}$ \\
\hline
\end{tabular}

*, deceased; **, No history of hot water epilepsy; aSP, simple partial; CP, complex partial; GC, generalized convulsions; SGC, secondary generalized convulsions; ${ }^{b} \mathrm{PWOH}$, pouring water over the head; TW, temperature of water; TB, termination of bath; ${ }^{\mathrm{c}} \mathrm{NE}$, neurological examination; $\mathrm{N}$, normal; MRI, magnetic resonance imaging

At first, he experienced simple partial seizures that were followed by nausea, dizziness and weird feelings when pouring hot water over his head. As his condition developed further, he experienced CPS characterized by the loss of contact accompanied by oral automatisms, staring gaze, and bimanual automatisms. At the age of 16, the patient began to experience CPS with secondary generalization while bathing. These CPS with secondary GTCS occurred once or twice over two to three years. The patient never experienced spontaneous seizures without bathing, and his bathing habits included the use of very hot water, which he would pour over his head. At the time of presentation, he had been taking $1200 \mathrm{mg}$ oxcarbazepin daily for one year. According to his history, he was seizure-free over the course of a year in which he substituted warm water for hot water. The patient had no childhood history of febrile seizure. Neurologic examination and interictal EEG were normal.

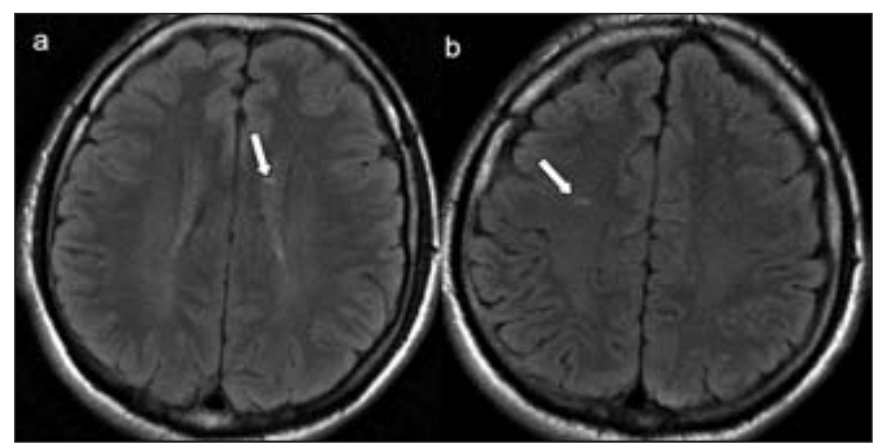

Figure 2: Transverse T2 weighted FLAIR images (a-b) of Patient 1. Arrows indicate some of the periventricular T2 hyperintense white matter lesions visible in both hemispheres.
Magnetic resonance imaging revealed T2 hyperintense lesions in the periventricular white matter; the orientations of some of these lesions were perpendicular to the ventricular axis (Figure 2). However, the lesions showed no contrast enhancement after intravenous gadolinium administration. Diffusion imaging for this patient was unremarkable.

The patient did not consent to a lumbar puncture procedure. Routine laboratory tests, electrocardiogram, echocardiogram, and carotid and vertebral Doppler sonography were normal. Due to the patient's age, additional laboratory tests were performed to rule out hypercoagulable disorder; all results were normal.

\section{Patient 2}

Patient 2, the 40-year-old sister of the index case, reported a history of CPS both with and without bathing. At the age of three, the patient had a febrile seizure. Between the ages of 7 and 23 , she experienced loss of consciousness with oral automatisms, pallor of the face, and staring as soon as she poured hot water over her head. This patient also experienced CPS spontaneously, but the seizures completely stopped after a three-year course of treatment with carbamazepin, beginning at 20 years of age.

Neurologic examination and interictal EEG were normal. Magnetic resonance imaging revealed small posterior parietal subcortical T2 hyperintense lesions, probably consistent with ischemic gliosis. She was not given intravenous gadolinium. Her diffusion MRI was within normal limits. Routine laboratory tests, electro-cardiogram, echocardiogram, carotid and vertebral Doppler sonography, and laboratory tests for hypercoagulable disorders were normal.

\section{Patient 3}

Patient 3, a 15-year-old male, experienced seizures only while bathing. Since the age of 7-8, he experienced CPS at the end of his bath. These seizures are characterized by nausea and 
vomiting with an aura accompanied by an unpleasant odor (valonia oak). These experiences were followed by cyanosis on the lips, loss of consciousness. Each seizure lasted approximately two to three minutes, and was followed by confusion, fatigue, weakness, and sleep. The patient had no history of anti-epileptic therapy. Over the two years prior to this study, the patient decreased the duration of his bathing sessions and used warm, rather than hot, water; subsequently, the frequency of his seizures decreased.

The patient had no childhood history of febrile seizure. Neurologic examination was normal. Interictal EEG revealed slow-wave activity within the theta range in both frontal regions, and sharp waves in the predominantly F4 electrode position. The patient did not consent to cranial MRI.

\section{Patient 4}

Patient 4, the 60-year-old father of the index case, died in 2007. He had suffered seizures from childhood until death. A clinical history was obtained from his wife and children, who had witnessed his seizures. According to their reports, the patient experienced three types of seizures. First, during baths, he experienced loss of contact with facial pallor and staring gaze, similar to his son. Second, he had seizures followed by oral automatisms, bimanual automatisms, slurred speech, and unusual body movements and postures (e.g., appearing hunchbacked) without bathing. Third, he experienced GTCS, usually while sleeping and occasionally occurring three or four times per night. His history revealed febrile seizures during childhood. His family reported that he was treated with phenytoin, which he took irregularly and at a possibly ineffective dose.

\section{Patient 5}

Patient 5, the 57-year-old mother of the index case, had experienced two or three GTCS per month, usually during sleep, since the age of 14 . The patient underwent phenytoin treatment for approximately 5-6 years. With the help of the drug, the patient's seizures were under control for approximately 7-8 years. However, at the age of 30 the patient began to experience one or two CPS per month. These seizures were characterized by an aura accompanied by abdominal sensations, an unpleasant odor, and anxiety; they were followed by loss of consciousness, oral automatisms, pallor, and staring. These seizures stopped spontaneously ten years ago.

The patient reported no history of HWS or febrile seizures. But the patient reported a history of systemic hypertension. Neurologic examination and interictal EEG were normal. Routine laboratory tests showed hypercholestrolemia.

The MRI revealed multiple T2 hyperintense white matter lesions localized bilaterally in the periventricular white matter, and in the right external capsule and right parietal subcortical white matter. No contrast enhancement was noted. Her diffusion MRI findings were normal.

\section{Patient 6}

Patient 6, the 53-year-old maternal uncle of the index case, had a history of GTCS that occurred while bathing in hot water. Before seizure onset, the patient would feel nauseated and hear

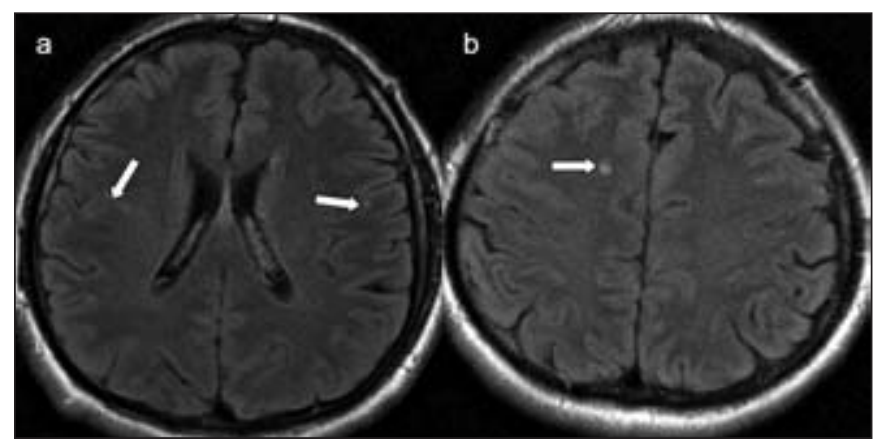

Figure 3: Transverse T2 weighted FLAIR images ( $a$ - $b$ ) for Patient 6 showing subcortical distribution of small T2 hyperintense lesions (arrows).

music. No spontaneous seizures were reported. The patient's seizures increased in frequency between the ages of 7 and 17. At the age of 17, the patient began substituting warm water for hot water; since that time, his seizures have decreased to one episode every one to three years.

The patient did not receive treatment for epilepsy and reported no history of febrile seizure. Neurologic examination and interictal EEG were normal. Cranial MRI revealed several small T2 hyperintense lesions in both parietal lobes (Figure 3). His diffusion MRI findings were within normal limits. We performed the laboratory tests administered to Patients 1 and 2, and all results returned normal.

\section{Patient 7}

This patient was the late grandfather of the index case. A clinical history was obtained from his daughters, who had observed his seizures. The patient's seizures were precipitated by pouring hot water over his head while bathing, and were characterized by nausea, vomiting, pallor, loss of conscious, and postictal drowsiness. The family could not recall whether their father had experienced spontaneous seizures.

\section{Patient 8}

Patient 8, the 73-year-old grandmother of the index case, had a ten-year history of weekly seizures. The age of initial seizures was not certain. These seizures were of two to three minutes in duration and were characterized by staring and pallor followed by cyanosis, oral automatisms, and loss of contact. She also experienced postictal confusion lasting 30 minutes. She had no history of anti-epileptic medication until the time of this study. Since childhood she had experienced nausea, strange sensations, weakness, and dizziness while bathing with hot water poured over her head or while spending time outdoors in hot weather. Because of these experiences, the patient refrained from bathing with hot water and largely avoided the outdoors during hot weather. She had two spontaneous GTCS in the past. Neurologic examination was normal.

The patient also reported a history of systemic hypertension. Interictal EEG revealed slow-wave activity within the theta range, which increased with hyperventilation, in the left 

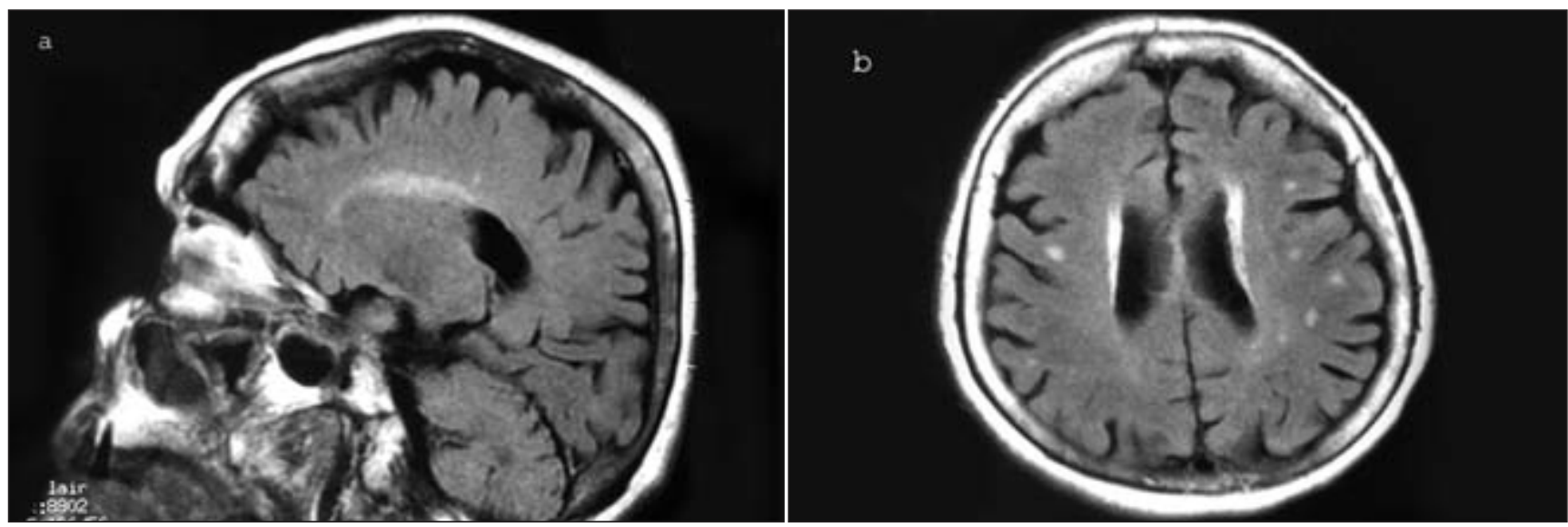

Figure 4: Sagital T2 weighted (a) and transverse T2 weighted (b) FLAIR images for Patient 8 demonstrating ischemic gliotic white matter lesions localized in the periventricular white matter and moderate cerebral atrophy.

frontotemporal area. Routine laboratory tests and carotid and vertebral Doppler sonography were normal. An electrocardiogram revealed atrial fibrillation.

Cranial MRI revealed mild to moderate cerebral atrophy and ischemic gliotic white matter lesions localized in the posterior periventricular white matter (Figure 4). Contrast scans showed no pathologic enhancement. Her diffusion MRI results were normal.

\section{Discussion}

We evaluated six generations of a Turkish family, which included one set of consanguineous parents and eight family members diagnosed with epilepsy. Of these, seven suffered from HWE. Moreover, cranial MRI performed on five of the six surviving patients revealed cerebral lesions.

The patients described here are similar to those described in other studies, particulary in terms of age at onset, seizure type, precipitating factors, and interictal EEG findings. Consistent with nearly all previous studies, we observed that males are affected more frequently than females (i.e. five male versus two female patients) $)^{1,5,7,14}$. The pathophysiological mechanisms underlying this finding or pattern of sex linkage inheritance have not yet been explained.

Our data concerning age at HWE onset (i.e. a range during childhood) and seizure semiology (i.e. the relative frequency of CPS) are consistent with previous studies ${ }^{1,5,7,14}$, which reported the ratio of CPS in HWE as high as $67-80 \%$. Furthermore, the ratio of concomitant spontaneous non-reflex seizures has been reported in $16-100 \%$ of patients ${ }^{1,5,7,14}$. In this family, seven members were diagnosed with HWE. Consistent with the literature, spontaneous seizures (in addition to reflex seizures) were observed in three family members.

Interictal EEG revealed abnormalities which were sharp waves and slow waves in Patient 3 and Patient 8 , respectively. Patient 3 had HWE alone, but the other patient had HWE as well as other types of epilepsy. All of the our patients had no video moniterization. Interictal EEG results were usually normal, although $15-20 \%$ might show diffuse abnormalities ${ }^{1}$. Interictal
EEG results were consistent with the literature in our cases. Interestingly, two studies conducted in Turkey reported the incidence of EEG abnormalities in HWE to be as high as $60 \%$ and $40.9 \%^{5,7}$.

Several studies on HWE support the possible aetiological contribution of aberrant thermoregulation, within the context of coexisting enviromental influences and the genetically susceptible population ${ }^{1,14}$. However, the exact pathogenic and genetic mechanisms underlying the expression of HWE in humans have not been clearly demostrated thus far.

Familial HWE cases with more than one affected member have been noted in 7-15\% of Indian probands. Among the 279 HWE patients reported in South India, there were three dizygotic twins, each with one member affected ${ }^{1,14}$. Hot water epilepsy was intra-familial in $18 \%$ of the cases in a descriptive epidemiological study conducted in rural parts of Bangalore, South India. This study included one family in which all seven members were diagnosed with $\mathrm{HWE}^{1,14,15}$.

To our knowledge, the family described in this study has the second largest number of members diagnosed with HWE identified so far. Satishchandra et $\mathrm{al}^{1}$ reviewed their case series for intra-familial HWE, and found five families with two to three members manifesting HWE. Savitha et $\mathrm{al}^{10}$ recently reported family histories of HWE among $32.4 \%$ of 71 patients with HWE. Bebek et $\mathrm{al}^{5}$ reported that $10 \%$ of their cases had a history of HWE. However, neither Bebek et al nor Savitha et al reported how many members of the same family were also affected. None of the patients in a study by Yalçin et $\mathrm{al}^{7}$ had a family history of HWE. A single case of HWE in a Japanese monozygotic co-twin was reported by Itoh et $\mathrm{al}^{1}$.

Using a mouse model of HWE, Ullal et al ${ }^{14}$ suggested that patients with HWE may have a genetically determined aberrant thermoregulatory system that causes extreme sensitivity to rapid increases in temperature, which occurs while bathing in hot water; this aberration may precipitate seizures. Other studies in rats showed that repeated hot water stimuli had a kindling-like effect, most notably on the amygdala; this produced a progressive increase in convulsive responses to stimulation ${ }^{1,5,14}$. 
Although primarly precipitating factors for seizures were pouring water over the head and temperature of water in reported series and in our family, the importance of water temperature in precipitating seizures has yet to be elucidated. In Indian patients, seizures were precipitated by water temperatures ranging from $40-50^{\circ} \mathrm{C}^{1,14}$. However, Ioos et al ${ }^{16,17}$ described French patients who experienced seizures in water with temperatures around $37^{\circ} \mathrm{C}$. The authors pointed out that patients of Caucasian descent may differ from those described in studies conducted in southern India ${ }^{11,16,17}$. Auvin et $\mathrm{l}^{18}$ described a patient who also experienced seizures triggered by a water temperature of around $33^{\circ} \mathrm{C}$. Seneviratne et $\mathrm{al}^{19}$ described a patient in whom seizures were precipitated by bathing, irrespective of the water temparature; both hot and cold water were able to precipitate seizures. These data suggest that different populations may have differing clinical presentations and/or genetic backround of HWE.

Whereas earlier published reports have suggested a polygenic mode of inheritance, autosomal dominant inheritance with low penetrance, or autosomal recessive inheritance ${ }^{14}$, the precise mode of inheritance remains unknown. In a study examining the genetics of HWE, Sinha et al postulated that autosomal recessive mutation is a distinct possibility. They speculated that, although the frequency of such a mutation in a particular individual would be fairly low, the high frequency of consanguineous marriage in many Indian families (and the Turkish family presented here) could lead to a marked increase in the appearance of HWE within these populations. However, they also noted that a singlelocus model is insufficient to explain genetic linkage of this sort. The authors pointed out an autosomal recessive model of inheritance with the possibility of concurrence of modifier gene(s) or of environmental factors ${ }^{1,14}$. It is likely to conform with the autosomal dominant genetic inheritance represented in the pedigree of this family. This notion is based on observations that this disease has emerged within each generation, has occurred in female and male individuals with no gender differences, and has been transmitted from father to son. Nevertheless, the proportion of penetrance in this family is high (i.e., over 80\%), which is inconsistent with the relationship between autosomal dominance and reduced penetrance in determining genetic inheritance.

Although no definite data are available, the temporal lobe is thought to be involved in the epileptogenesis of HWE. The literature does, however, include a few reports of EEG ictal recordings showing paroxysmal activity in this cortical area ${ }^{1,7,11}$. Ullal et $\mathrm{al}^{20}$ recorded hippocampal hypersynchronous discharges in adult rats submitted to repeated exposure to hot water to the head $^{20}$. Syzmonowicz and Merloff suggested the possible existence of structural lesions in the temporal lobe of these patients; however, CT/MRI studies have not detected lesions of this nature ${ }^{21}$. In this context, Satishchandra et $\mathrm{al}^{1}$ performed an ictal and interictal single photon emission computed tomography study in ten patients with HWE, and demonstrated ictal hypermetabolic uptake in the medial temporal structures and hypothalamus on the left in three patients, and on the right in two patients.

Several case reports have reported neuroimaging data indicating the presence of structural cerebral lesions (e.g., hippocampal sclerosis, hippocampal/parahippocampal atrophy, pineal cysts, cavum septum pellucidi, cortical dysplasia, and arachnoid cysts) in HWE patients s, $^{2,11,12}$. In our study, the MRI findings pertaining to Patient 8 may be attributable to ischemic changes, considering her advanced age and vascular risk factors (e.g., hypertension and atrial fibrillation). We found several small T2 hyperintense lesions, probably consistent with ischemic gliosis, in Patients 2 and 6. However, we were unable to identify the exact nature of lesions in Patient 1 , either demyelinating or ischemic.

Experiments with rats involving repeated exposure of their heads to hot water show increased susceptibility to convulsions. Research has shown ischemic changes in specific areas, such as Sommer's sector in the hippocampus, neural layers 4 and 5 of the cerebral cortex, and reticular neurons in the brain stem, in response to such stimulation. These phenomena produced a kindling-like effect, primarily in the amygdala ${ }^{8,22,23}$.

Moreover, Ilbay et $\mathrm{al}^{24}$ investigated the status of the bloodbrain barrier and the roles of blood pressure and body temperature during the induction of HWE in rats. They found that hot water-induced seizures increased cerebrovascular permeability. Although high blood pressure and hyperthermia contributed to permeability, seizure activity was the major factor in this change.

In a pathological study of four confirmed human patients with HWE, distinct hippocampal involvement, with gliosis and ischemic changes in the reticular nuclei of the brain stem, were observed in two cases. In the remaining two cases, a right thalamic glioma was observed in one patient, and cerebral atrophy with neuronal loss and gliosis in both sides of the hippocampus were observed in the other ${ }^{1,25}$.

We suggest the possibility that the cerebral lesions found in Patients 1,2, and 6 may be related to the etiopathogenetic mechanisms of HWE. We further suggest that the probability of the co-occurrence of these lesions and HWE may extend beyond chance, even if there is a no more than chance association between the presence of cerebral lesions and the epileptogenesis of HWE in Patient 8. In our opinion, these lesions in Patients 1, 2 , and 6 may represent permanent effects of hot water seizures. However, lacking neuropathologic data, it is difficult to establish whether the lesions derive from acquired impairments (e.g., infarcts of the white matter) or genetic determinants based on neuroradiological and clinical data alone.

In summary, descriptions of HWE-affected families with different ethnic backgrounds, and investigations using innovative neuroimaging methods, may yield more definite conclusions regarding the mechanisms of epileptogenesis, as well as the varying clinical presentations and nature of the genetic defects underpinning this disease. These data may provide increased insight into the treatment of HWE.

\section{REFERENCES}

1. Satishchandra P. Hot water epilepsy. Epilepsia. 2003;44:29-32.

2. Lee YC, Yen DJ, Lirng JF, Yiu CH. Epileptic seizures precipitated in a patient by immersing his right hand in hot water. Seizures. 2000;9:605-7.

3. Auvin S, Lamblin MD, Pandit F, Bastos M, Derambure P, Vallée L. Hot water epilepsy occurring at temperature below the core temperature. Brain Dev. 2006;28:265-8.

4. Kowacs PA, Marchioro IJ, Silva Jr EB, Rocha SF, Simão CA, Meneses MS. "Hot-water epilepsy," "warm-water epilepsy," or bathing epilepsy? Report of three cases and considerations regarding an old theme. Arq Neuropsiquiatr. 2005;63:399-401. 
5. Bebek N, Gurses C, Gokyigit A, Baykan B, Ozkara C, Dervent A. Hot water epilepsy: clinical and electrophysiologic findings based on 21 cases. Epilepsia. 2001;42:1180-4.

6. Incecik F, Hergüner MO, Elkay M, Altunbasak S. Hot water epilepsy - a report of three cases. Indian Pediatr. 2004;41:731-3.

7. Yalçin AD, Toydemir HE, Forta H. Hot water epilepsy: clinical and electroencephalographic features of 25 cases. Epilepsy Behav. 2006;9:89-94.

8. Tezer FI, Ertas N, Yalcin D, Saygi S. Hot water epilepsy with cerebral lesion: a report of five cases with cranial MRI findings. Epilepsy Behav. 2006;8:672-6.

9. Erdem E, Topcu M, Renda Y, Ciger A, Varli K, Zileli T. Hot water epilepsy. Clin Electroencephalogr. 1992;23:152-8.

10. Savitha MR, Krishnamurthy B, Ashok DA, Ramachandra NB. Self abortion of attacks in patients with hot water epilepsy. Indian Pediatr. 2007;44:295-8.

11. Grosso S, Farnetani MA, Francione S, Galluzzi P, Vatti G, Cordelli DM, et al. Hot water epilepsy and focal malformation of the parietal cortex development. Brain Dev. 2004;26:490-3.

12. Tajima Y, Minami N, Sudo K, Moriwaka F, Tashiro K. Hot water epilepsy with pineal cyst and cavum septi pellucidi. Jpn J Psychiatry Neurol. 1993;47:111-4.

13. Engel Jr J. A proposed diagnostic scheme for people with epileptic seizures and with epilepsy: report of ILAE task force on classification and terminology. Epilepsia. 2001;42:1-8.

14. Satishchandra P, Ullal GR, Sinha A, Shankar SK. Pathophysiology and genetics of hot-water epilepsy. In: Berkovick SF, Genton P, Hirsch E, Picard F, editors. Genetics of focal epilepsy. London: John Libbey; 1999. p. 1`69-76
15. Gururaj G, Satishchandra P. Correlates of hot water epilepsy in rural south India: a descriptive study. Neuroepidemiology. 1992;11: 173-9.

16. Ioos C, Fohlen M, Villeneuve N, Badinand-Hubert N, Jalin C, Cheliout-Heraut $\mathrm{F}$, et al. Hot water epilepsy: a benign and unrecognized form. J Child Neurol. 2000;15:125-8.

17. Ioos C, Villeneuve N, Fohlen M, Badinant-Hubert N, Jalin C, Cheliout-Heraut $\mathrm{F}$, et al. Hot water epilepsy: a benign and underestimated form. Arch Pediatr. 1999;6:755-8.

18. Auvin S, Lamblin MD, Pandit F, Bastos M, Derambure P, Vallée L. Hot water epilepsy occurring at temperatures below the core temperature. Brain Dev. 2006;28:265-8.

19. Seneviratne U. Bathing epilepsy. Seizure. 2001;10:516-7.

20. Ullal GR, Satishchandra P, Shankar SK, Dadlani R, Arshi I. Relationship of rectal \& hippocampal temperature profiles to seizure activity in rats prone \& resistant to hot water induced epilepsy. Indian J Med Res. 1998;108:279-84.

21. Szymonowicz W, Meloff KL. Hot water epilepsy. Can J Neurol Sci. 1978;5:247-51.

22. Ullal GR, Satishchandra P, Shankar SK. Hyperthermic seizures: an animal model for hot-water epilepsy. Seizure. 1996;5:221-8.

23. Klaunberg BJ, Sparber SB. A kindling like effect induced by repeated exposure to heated water in rats. Epilepsia. 1984;25: 292-301.

24. Ilbay G, Sahin D, Ates N. Changes in blood-brain barrier permeability during hot water-induced seizures in rats. Neurol Sci. 2003;24:232-5.

25. Shankar SK, Satishchandra P. Autopsy study of brains in hot water epilepsy. Neurology (India). 1994;42:56-7. 